\title{
openheart Maternal ethnicity and its impact on the haemodynamic and blood pressure response to labetalol for the treatment of antenatal hypertension
}

\author{
D Stott, ${ }^{1}$ M Bolten, ${ }^{1}$ D Paraschiv,${ }^{1}$ I Papastefanou, ${ }^{2}$ J B Chambers, ${ }^{3}$ \\ N A Kametas ${ }^{1,4}$
}

To cite: Stott $D$, Bolten $M$ Paraschiv D, et al. Maternal ethnicity and its impact on the haemodynamic and blood pressure response to labetalol for the treatment of antenatal hypertension. Open Heart 2016;3:e000351. doi:10.1136/openhrt-2015000351

- Additional material is available. To view please visit the journal (http://dx.doi.org/ 10.1136/openhrt-2015000351).

Received 8 October 2015 Revised 8 February 2016 Accepted 14 February 2016

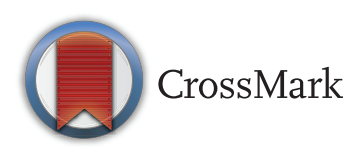

${ }^{1}$ Division of Women's Health, Antenatal Hypertension Clinic, King's College Hospital,

London, UK

${ }^{2}$ Leto Maternity Unit, Athens, Greece

${ }^{3}$ Cardiothoracic Centre, Guy's and St Thomas Hospital,

London, UK

${ }^{4}$ Division of Women's Health, Harris Birthright Research Centre for Fetal Medicine, King's College Hospital, London, UK

Correspondence to Dr NA Kametas; nick.kametas@kcl.ac.uk

\section{ABSTRACT}

Objective: Blood pressure (BP) control outside pregnancy is associated with a reduction in adverse cardiovascular events, and in pregnancy with improved outcomes. Outside pregnancy, there is evidence $\beta$ blockers are less effective in controlling BP in black populations. However, in pregnancy, labetalol is recommended as a universal first-line treatment, without evidence for the impact of ethnicity on its efficacy. We sought to compare haemodynamic responses to labetalol in black and white pregnant patients.

Methods: This was a prospective observational cohort study in a London teaching hospital. Maternal haemodynamics were assessed in 120 pregnant women treated with labetalol monotherapy.

Measurements were taken at presentation, 1 and $24 \mathrm{~h}$ after treatment. Participants were monitored regularly until delivery. Statistical analysis was performed by multilevel modelling.

Results: Both groups exhibited similar temporal trends in haemodynamic changes over the first $24 \mathrm{~h}$ following labetalol. Both showed a reduction in BP and peripheral vascular resistance within $1 \mathrm{~h}$ and in heart rate after $24 \mathrm{~h}$. There was no change in cardiac output and stroke volume in either group. BP control $(<140 /$

90) was achieved at $1 \mathrm{~h}$ in $79.7 \%$ of the white and $77 \%$ of the black cohort. At $24 \mathrm{~h}$, control was achieved among $83.1 \%$ and $63.9 \%$, and up to the immediate intrapartum period control was achieved in $89.8 \%$ and $70.4 \%$ of white and black patients, respectively.

Conclusions: There is no difference in the acute haemodynamic changes and hypertension can be controlled throughout pregnancy with labetalol monotherapy in excess of $70 \%$ pregnant black and white patients.

\section{INTRODUCTION}

Hypertension affects at least one-quarter of the UK adult population. ${ }^{1}$ It is the largest single contributor to the worldwide burden of death and disease, and is responsible for 9.4 million deaths annually. ${ }^{2}$

\section{KEY QUESTIONS}

What is already known about this subject?

- Blood pressure control is generally associated with a reduction in cardiovascular events and improved pregnancy outcomes. Outside pregnancy, there is evidence $\beta$-blockers are less effective in controlling BP in black populations. However, in pregnancy, labetalol is recommended as a first-line treatment, without evidence for the impact of ethnicity on its efficacy.

What does this study add?

- In the acute phase following oral labetalol treatment for hypertension in pregnancy, both black and white populations exhibit similar haemodynamic changes. Hypertension can be controlled acutely in $80 \%$ of both black and white pregnant patients, but sustained control throughout pregnancy is achieved in about $90 \%$ of white and $70 \%$ of black patients, respectively.

How might this impact on clinical practice?

- First-line antihypertensive treatment in pregnancy with labetalol is effective in controlling blood pressure acutely both in white and black populations. Therefore, ethnicity should not be used as a prime determinant in selecting antihypertensive therapy in pregnancy. In both black and white populations, there will be a significant proportion of patients who do not respond to labetalol and will need additional vasodilatory medications.

Black populations in the UK are disproportionately affected by hypertension. Mortality among Caribbean-born UK residents from hypertension-related conditions is 3.5 times the national rate. ${ }^{3}$

Treatment of hypertension dramatically reduces adverse events such as stroke and coronary artery disease. Even modest reductions in blood pressure (BP) markedly lower the risk of mortality from heart disease and stroke. ${ }^{4}$ 
Outside of pregnancy, the rationale for the treatment of hypertension has been based on considerations of age and ethnicity. For example, the 2011 National Institute for Health and Care Excellence (NICE) guidance, on the treatment of hypertension, states that younger hypertensive patients should be started on an ACE inhibitor or an angiotensin receptor blocker, while in older patients or those of African or Afro-Caribbean origin, initial therapy should be with a calcium channel blocker. ${ }^{5}$

This NICE clinical algorithm reflects evidence showing ethnic differences in the mechanisms underlying hypertension. Brown ${ }^{6} 7$ has suggested hypertension may be broadly divided into two categories, a low renin, volume expanded and high-total sodium state, and another, with a high renin, vasoconstricted state.

There are ethnic variations in the expression of renin, with black populations tending to have lower renin than white populations. ${ }^{68}$

Since $\beta$-blockers exert their effect primarily by lowering the production of renin by the kidney, ${ }^{6} 9$ it is unsurprising that their effectiveness has been shown to be reduced in black populations. The ASCOT (Anglo-Scandinavian Cardiac Outcomes Trial) showed that black people demonstrate less of a fall in BP compared with white people following atenolol treatment ${ }^{10}$ and they respond better to calcium channel blockers and diuretics. ${ }^{10}$

In contrast to the NICE guidance on the management of hypertension outside pregnancy, guidance for treatment in pregnancy recommends all women should be offered labetalol, a non-selective $\beta$-blocker which also has $\alpha$-blocking properties, ${ }^{11}$ as first-line therapy. ${ }^{5}$ Data regarding its efficacy within pregnancy in different ethnic groups are lacking.

In this study, we examined if there was a difference in the BP and haemodynamic responses between black and white pregnant women who had been started on labetalol treatment. We wanted to assess if the ethnic differences reported in response to $\beta$-blockade outside of pregnancy are mirrored in pregnancy, or if gestational cardiovascular changes neutralise these ethnic variations.

\section{METHODS}

\section{Study population}

King's College Hospital, London, provides a dedicated clinic for the management of hypertension in pregnancy.

In this prospective observational cohort study, we assessed 120 pregnant women who presented consecutively to this clinic with hypertension requiring treatment, between January 2013 and May 2014. Treatment was started with labetalol when BP was greater than $150 / 100 \mathrm{~mm} \mathrm{Hg}$, or greater than $140 / 90 \mathrm{~mm} \mathrm{Hg}$ with evidence of end-organ damage as per the NICE recommendations. ${ }^{5}$

At initial presentation, maternal demographics and haemodynamics were assessed as described below. Study participants were followed up at 1 and $24 \mathrm{~h}$ after treatment and regularly thereafter until delivery in order to titrate the labetalol dosage and ensure optimal BP control. The decision was taken to review BP and haemodynamic indices after $1 \mathrm{~h}$ because of the third trimester pharmacokinetics of labetalol, which reaches a peak concentration approximately 20-60 min after ingestion. $^{12}$

The study was approved by the local ethics committee (NRES Committee London-Fulham, REC reference: 12/LO/1593). Written informed consent was obtained from the participants.

\section{Outcome measures}

The main outcome measure was a therapeutic drop in $\mathrm{BP}$ with labetalol monotherapy, defined as a fall in $\mathrm{BP}$ to below 140/90. This was recorded at 1 and $24 \mathrm{~h}$ after treatment. Participants were reviewed regularly for BP control just before the intrapartum period was recorded. Unsuccessful treatment with labetalol monotherapy was defined as BP consistently above $140 / 90 \mathrm{~mm} \mathrm{Hg}$ despite maximisation of labetalol dosage to $2400 \mathrm{mg}$ /day and the need for additional vasodilatory therapy.

Haemodynamic parameters such as cardiac output (CO), stroke volume (SV) and peripheral vascular resistance (PVR) were assessed before treatment, 1 and $24 \mathrm{~h}$ after treatment.

Outcome data, including diagnoses such as preeclampsia (hypertension with proteinuria), pregnancy-induced hypertension (hypertension without proteinuria) and birth weight centiles were recorded from local records. The definition of pre-eclampsia (PE) was that of the International Society for the Study of Hypertension in Pregnancy. ${ }^{13}$ Gestational age was estimated from the first trimester ultrasound and birth weight centiles were calculated as described by Royston and Wright ${ }^{14}$ using locally derived birth weight reference ranges.

\section{Maternal history}

The following maternal demographics were recorded: age, weight, height, body mass index, body surface area (BSA), cigarette smoking during pregnancy, medical history (including chronic hypertension, asthma, renal disease, diabetes mellitus), medication (including antihypertensives, antiasthmatics, antidiabetics), parity (nulliparous, parous with no previous hypertension in pregnancy, parous with previous hypertension in pregnancy). Women of African or Afro-Caribbean descent were recorded as 'black' and women who gave their ethnicity as Caucasian or European were recorded as 'white'. Women who self-reported their ethnicity other than Caucasian or black African or black Caribbean were excluded from the present study.

\section{Maternal haemodynamic measurements}

Maternal cardiac function was assessed with a noninvasive CO monitor using bioreactance technology 
(NICOM, Cheetah Medical Ltd, Maidenhead, Berkshire, $\mathrm{UK}){ }^{15}$

In 20 patients, paired measurements were taken for maternal SV and CO by echocardiography as previously described $^{16}$ by one operator (NAK) and the bioreactance monitor.

BP was measured in accordance with the British Hypertension Society guidance, ${ }^{17}$ with an automated device validated for use in pregnancy and PE (Microlife Watch BP Office AFIB, equivalence with Microlife Watch BP Home).${ }^{18}$ During regular follow-up visits compliance was monitored. Admission to hospital was arranged in cases of suspected suboptimal compliance.

\section{Statistical analysis}

The normality of the data's distribution was assessed by the Kolmogoroff-Smirnoff test. For continuous numerical data, the Mann-Whitney $\mathrm{U}$ test or the unpaired t test were used to compare non-normally and normally distributed data, respectively. For categorical variables, the $\chi^{2}$ test was used to assess the differences in proportions between groups.

A multilevel mixed effects linear model was fitted due to the longitudinal structure of the data as described by Royston and Altman. ${ }^{19}$ We aimed to examine the possible effect of ethnicity on the haemodynamic parameters and the BP.

Multilevel modelling assumes that fixed intercepts and coefficients are the same across different levels while random intercepts and coefficients are allowed to vary across different levels. Specifically, we fitted a fixed slopes random intercept model which takes the general form:

$$
\begin{aligned}
& Y i j=b 0 j+b 1 X i j+\varepsilon i j \\
& b 0 j=b 0+u 0 j
\end{aligned}
$$

Time, age, height, weight, BSA, parity and ethnicity were inserted as independent parameters in the fixed part of the model. Time was an ordinal parameter that represented the three phases of the study (prior to, $1 \mathrm{~h}$ after and $24 \mathrm{~h}$ after treatment) and had values of 1, 2 and 3 . The random part component was a random-intercept model that included level 1 . The group of repeated measurements for each participant constituted level 1 and each measurement constituted residual random variance. Essentially this type of analysis enabled us to take into account the dependency (correlation) between the repeated measurements, and the residual variance between participants

We used a restricted maximum likelihood algorithm to parameterise the model. Akaike information criterion and Bayesian information criterion were used to compare intermediate models.

The statistical software packages SPSS (IBM Corp Released 2010. IBM SPSS Statistics for Windows, V.19.0, Armonk, New York, USA: IBM Corp) and STATA
(StataCorp 2013. Stata Statistical Software: Release V.13, College Station, Texas, USA: StataCorp LP) were used for the data analysis.

\section{RESULTS}

Maternal demographics, haemodynamic indices and pregnancy outcomes for the study's black and white cohorts are presented in table 1 .

The patients in this study were consecutive attendees of the antenatal hypertension clinic. Their distribution broadly mirrors the distribution of black and white women in the antenatal population in our catchment area in South London.

Black participants had a significantly greater BSA, were heavier and were significantly more likely to be multiparous. They were also significantly more likely to present with hypertension earlier compared with white participants. There was no difference between the groups in other maternal demographics, or in the prevalence of coexisting medical problems.

There was no difference in the prevalence of preeclampsia or pregnancy-induced hypertension. Black women had significantly lighter babies, both in terms of absolute values and in terms of gestation-adjusted birth weight centiles.

There was no difference between the groups in their response rates to labetalol at $1 \mathrm{~h}$, with almost $80 \%$ of both black and white patients having a therapeutic response. There was a significant difference in response rates at $24 \mathrm{~h}$ and up to the immediate intrapartum period. However, labetalol remained effective in controlling BP up until delivery in over $70 \%$ of the black study participants.

The haemodynamic variables of the two groups at presentation and following labetalol treatment are presented in table 2 and in figures 1 and 2. There was no significant difference in the haemodynamic variables between the groups at presentation, or at $1 \mathrm{~h}$ after labetalol therapy. At $24 \mathrm{~h}$ following labetalol therapy, white women had slightly lower diastolic BP (DBP) than black patients. There was no significant difference between the two groups in their other haemodynamic variables at $24 \mathrm{~h}$ after therapy.

The results of the longitudinal data analysis for $\mathrm{CO}$, heart rate (HR), SV, mean arterial pressure (MAP) and PVR are presented in tables 3 and 4 and in figures 1 and 2 (the remaining variables are attached as online supplementary tables S1 and S2).

Our analysis showed that ethnicity, as an explanatory parameter of the model's fixed part, did not have a significant association with the examined parameters, namely CO, CI, HR, SV, Stroke volume index, MAP, systolic BP (SBP), DBP and PVR (tables 3 and 4).

The fixed part of the multilevel modelling showed a robust fixed inverse relation between MAP and the time of the study. Similar trends were identified for SBP, DBP and PVR. A significant reduction in these variables was 
Table 1 Maternal demographic and haemodynamic variables and pregnancy outcomes

\begin{tabular}{|c|c|c|c|}
\hline Variable & White $(n=59)$ & Black $(n=61)$ & p Value \\
\hline Age (years) & $31.3(5.9)$ & $31.6(6.1)$ & 0.7 \\
\hline Height (cm) & $167.1(7.0)$ & $165.1(6.3)$ & 0.1 \\
\hline Weight (kg) & $75.1(68.8-84.2)$ & $82.8(72.5-94.9)$ & 0.008 \\
\hline Body surface area $\left(\mathrm{m}^{2}\right)$ & $1.8(0.1)$ & $1.9(0.1)$ & 0.03 \\
\hline Smoking, $\mathrm{n}(\%)$ & - & - & \\
\hline Spontaneous conception, n (\%) & $43(72.9)$ & $42(68.9)$ & 0.6 \\
\hline \multicolumn{4}{|l|}{ Parity } \\
\hline Nulliparous, n (\%) & $44(74.6)$ & $27(44.3)$ & 0.001 \\
\hline Parous-previous PE, n (\%) & $10(16.9)$ & $15(24.6)$ & 0.3 \\
\hline Parous-no previous PE, n (\%) & $5(8.5)$ & $19(31.1)$ & 0.003 \\
\hline \multicolumn{4}{|l|}{ Medical history } \\
\hline Chronic hypertension, n (\%) & $6(10.2)$ & $14(23)$ & 0.08 \\
\hline Asthma, n (\%) & $2(3.4)$ & $1(1.6)$ & 0.6 \\
\hline Renal-cardiac disease, n (\%) & $3(5.1)$ & $3(4.9)$ & 1.0 \\
\hline Gestational age at presentation (weeks) & $34.5(7.1)$ & $31.2(9.3)$ & 0.03 \\
\hline \multicolumn{4}{|l|}{ Pregnancy outcome } \\
\hline Gestational age at delivery (weeks) & $38.1(1.8)$ & $37.5(2.8)$ & 0.07 \\
\hline Birth weight $(\mathrm{g})$ & $3204.6(597.3)$ & $2899.9(763.2)$ & 0.01 \\
\hline Birth weight centile & $58.3(24.6-77.1)$ & $32.3(10.0-56.7)$ & 0.01 \\
\hline Pre-eclampsia, n (\%) & $24(40.7)$ & $28(45.9)$ & 0.5 \\
\hline Early pre-eclampsia (before 34 weeks) & $1(1.7)$ & $4(6.5)$ & 0.2 \\
\hline Intermediate pre-eclampsia (34-37 weeks) & $3(5.1)$ & $8(13.1)$ & 0.7 \\
\hline Late pre-eclampsia (after 37 weeks) & 20 (33.9) & $16(26.2)$ & 0.4 \\
\hline Pregnancy-induced hypertension, n (\%) & $29(49.2)$ & $21(34.4)$ & 0.1 \\
\hline Response in $1 \mathrm{~h}, \mathrm{n}(\%)$ & $47(79.7)$ & $47(77)$ & 0.8 \\
\hline Response at $24 \mathrm{~h}, \mathrm{n}(\%)$ & $49(83.1)$ & 39 (63.9) & 0.02 \\
\hline Response up to delivery, $\mathrm{n}(\%)$ & $53(89.8)$ & $43(70.4)$ & 0.007 \\
\hline
\end{tabular}

seen from as early as $1 \mathrm{~h}$ and maintained at $24 \mathrm{~h}$ after treatment (tables 2-4, figure 1). In addition, HR reduced with time, a decline seen at $24 \mathrm{~h}$ (tables 2-4, figure 2). Furthermore, the fixed part of the multilevel modelling revealed significant associations between $\mathrm{CO}$, CI, PVR and parity, whereas SV was positively related to maternal height (tables 3 and 4).

The mean difference and limits of agreement between echocardiography and the bioreactance monitor were -0.4 (-22.6 to 21.8) and 0.1 (-2.1 to 2.3) for SV and $\mathrm{CO}$, respectively.

\section{DISCUSSION}

This study shows black and white women demonstrate a similar haemodynamic response over the first $24 \mathrm{~h}$ following labetalol treatment for antenatal hypertension. Maternal ethnicity was not an independent predictor of the change over time of haemodynamic variables following treatment with labetalol, even after adjusting for maternal anthropometric variables that are known to affect cardiac indices. ${ }^{20}$ This is also reflected in the fact that both groups demonstrated a nearly $80 \%$ response rate at $1 \mathrm{~h}$ following treatment.

Good response rates were also observed at $24 \mathrm{~h}$ and up until delivery in both groups, but there was a slight attenuation of the efficacy of labetalol in black women. White women demonstrated a sustained therapeutic response at $24 \mathrm{~h}$ and the majority of black women also demonstrated this therapeutic response, but the proportion reaching this therapeutic target was slightly lower $(60 \%)$. Similarly, a $20 \%$ difference in BP control between the two groups was observed until delivery, with about $70 \%$ of black women and $90 \%$ of white women maintaining control with labetalol monotherapy.

Our study also demonstrated CO increases with parity, irrespective of whether this previous pregnancy was complicated by hypertension. This is in keeping with our previous work showing parous women have a higher CO. ${ }^{21}$ Possible proposed mechanisms for this haemodynamic difference include cardiac remodelling which fails to regress following the first delivery, or an earlier and exaggerated response to the hyperdynamic stimuli of early pregnancy.

\section{Previous work on $\boldsymbol{\beta}$-blockers}

In keeping with other work examining the effects of $\beta$-blockers outside of pregnancy, ${ }^{11}{ }^{22}$ we found labetalol lowers heart rate, reduces vascular resistance and does not significantly reduce $\mathrm{CO}$. The reduction in vascular resistance has been ascribed to the $\alpha$-blocking effect of labetalol, ${ }^{23}$ which is a mixed $\beta$-blocker and $\alpha$-blocker. 


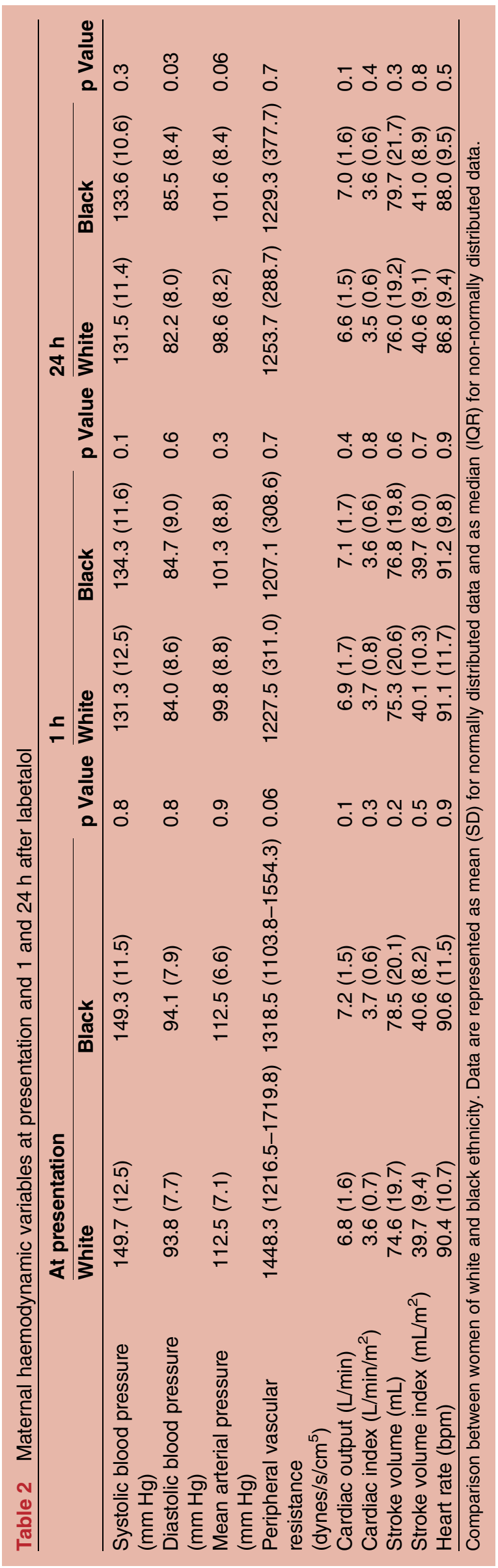

However, the $\beta$-blockade effect of labetalol is four to six times stronger than its $\alpha$-antagonist effect. ${ }^{23}$

In contrast to other studies investigating the efficacy of $\beta$-blockers outside of pregnancy, we have found that labetalol is effective in controlling BP both in white and black women during pregnancy, albeit with a slightly lower rate of sustained control in black patients.

That black ethnic groups respond less well to $\beta$-blockers outside pregnancy has been demonstrated in several studies. A substudy of the ASCOT trial compared the BP response in over 5000 hypertensives of either European, African and South-Asian origin, who were randomised to receive either atenolol or amlodipine. This study found that black participants responded less well to atenolol compared with other ethnic groups, and during the monotherapy period black participants actually showed an increase in SBP. ${ }^{10}$ Other studies have similar findings: a randomised double-blind study among 1292 hypertensives in the USA showed that black patients were less likely than other racial groups to exhibit a therapeutic response to atenolol. This lack of efficacy was particularly evident among older black patients, of whom only $33 \%$ achieved a therapeutic response. ${ }^{24}$

A systematic review from 2004 examining the efficacy of different antihypertensives in reducing BP, morbidity and mortality in black patients concluded that $\beta$-blocker monotherapy in black patients showed no significant difference over placebo in the reduction of SBP. ${ }^{25}$

There is not, however, universal consensus on the potency of ethnic difference in determining the response to antihypertensive therapy: another systematic review by Sehgal found that $90 \%$ of both Caucasians and African-Americans had a similar response in DBP with $\beta$-blockers, and this analysis suggested that studies purporting to show a lower rate of response to therapeutic targets with $\beta$-blockade among black patients may in fact be due to their higher baseline BPs. It is noteworthy that in our study the two cohorts had similar BPs at presentation. Like our data, this meta-analysis found generally a worse response to $\beta$-blockers among black compared with white patients, but given the degree of overlap between groups, this analysis concluded that ethnicity should not be used as a single determinant of treatment. $^{26}$

As with $\beta$-blockers in general, there are conflicting reports on the specific efficacy of labetalol in black populations. A study of 65 black and 75 white patients by Flamenbaum $e t a l^{27}$ found that labetalol was not significantly different between black and white hypertensives in its antihypertensive effect, whereas propranolol, a $\beta$-blocker which does not have an $\alpha$-blockade action, was significantly less effective in black hypertensives. It may be hypothesised therefore that the efficacy of labetalol in black populations arises from its vasodilatory $\alpha$-blockade action, independently of its $\beta$-adrenergic antagonism, which may be somewhat renin dependent. We note, however, that although this study did not show 

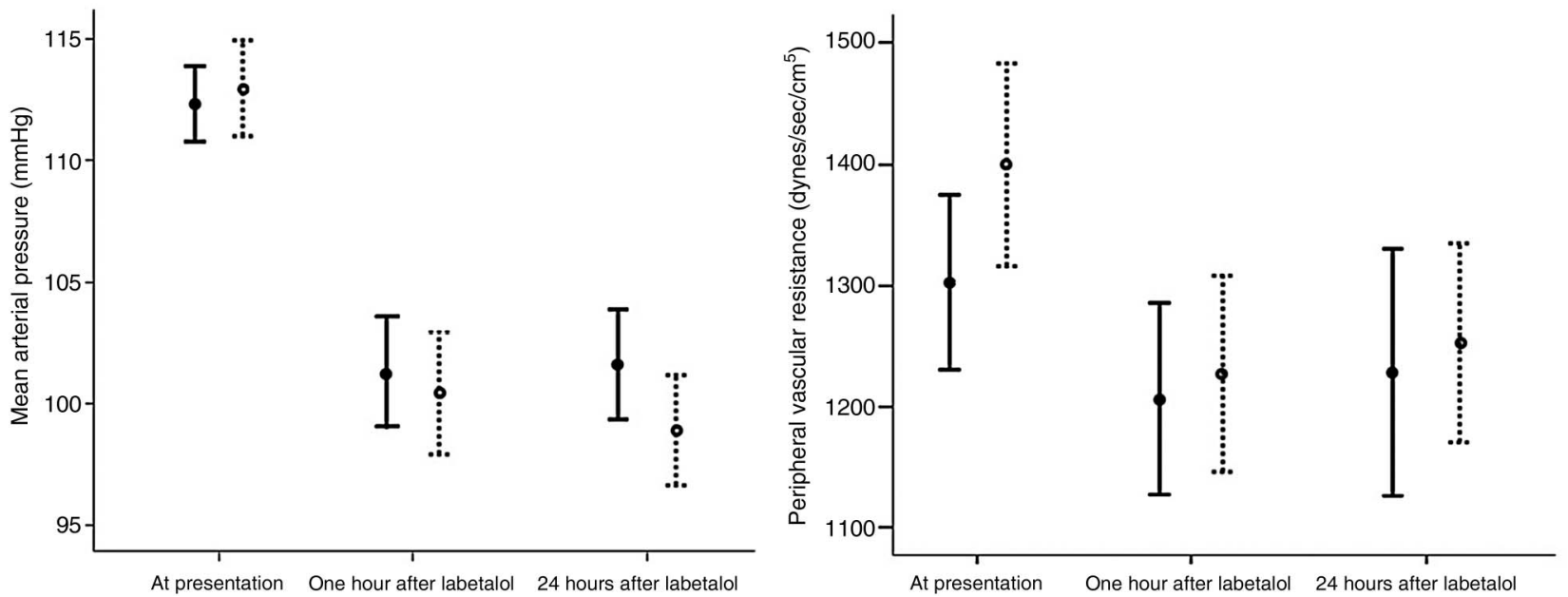

Figure 1 Longitudinal changes in mean arterial pressure (left) and peripheral vascular resistance (right) at presentation, at 1 and at $24 \mathrm{~h}$ following treatment with labetalol. Data are presented as mean and SE of the mean. The solid lines represent black patients, while the dashed lines white patients.

a statistically significant difference between the response to labetalol between white and black ethnic groups, there was a trend towards labetalol being more effective among white patients, compared with black patients. A smaller study by Lucas et $a t^{28}$ reported in 61 patients equal efficacy between labetalol and hydrochlorthiazide among black patients.

On the contrary, a larger multicentre study by Townsend et al, comparing the efficacy of labetalol versus atenolol in 292 black and white hypertensives found that labetalol was significantly more effective in white compared with black populations. Indeed, this study found that there was, in fact, a small increase in the supine SBP among black hypertensives following labetalol therapy, that higher doses of labetalol were required among black populations to achieve BP control, and that atenolol was markedly more effectively than labetalol in lowering supine BPs among black patients. ${ }^{29}$ We also note a smaller study from Jennings and Parsons ${ }^{30}$ which also shows that labetalol was more effective in white populations.

\section{Pathophysiology of hypertension in black populations}

$\beta$-Blockers exert their action through three mechanisms, including a vasodilatory action, a central cardiac negative chronotropic and inotropic effect and via inhibition of renin release from the kidney's juxtaglomerular cells, resulting in an attenuation of the activity of the renin-angiotensin-aldosterone system. The latter mechanism appears to be the cardinal pathway of BP control with $\beta$-blockers, ${ }^{9}$ and hence testing for renin levels has been proposed as a sensitive screening tool to anticipate the efficacy of these drugs in hypertension. ${ }^{7}$ There is evidence that hypertensives with high or normal renin
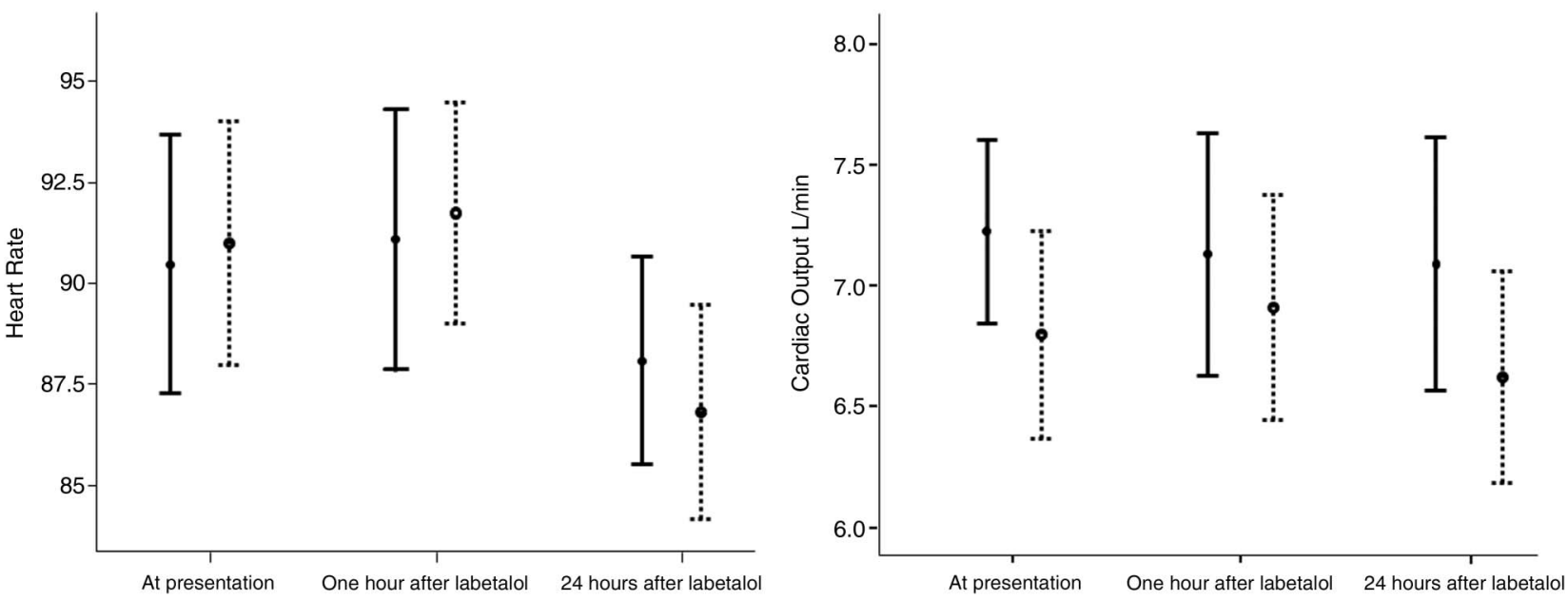

Figure 2 Longitudinal changes in heart rate (left) and cardiac output (right) at presentation, at 1 and at $24 \mathrm{~h}$ following treatment with labetalol. Data are presented as mean and SE of the mean. The solid lines represent black patients, while the dashed lines white patients. 
Table 3 Summary of multilevel linear mixed-effects models for mean arterial pressure and peripheral vascular resistance

\begin{tabular}{|c|c|c|c|c|}
\hline \multirow[b]{2}{*}{$\begin{array}{l}\text { Variable } \\
\text { Fixed part }\end{array}$} & \multicolumn{2}{|c|}{ Mean arterial pressure } & \multicolumn{2}{|c|}{ Peripheral vascular resistance } \\
\hline & Estimate (SE) & p Value & $\begin{array}{l}\text { Estimate (SE) } \\
\text { Fixed part }\end{array}$ & p Value \\
\hline Intercept & $117.41(14.95)$ & $<0.001$ & 4005.53 (566.5732) & $<0.001$ \\
\hline Time & $-6.28(0.50)$ & $<0.001$ & $-62.95(12.06)$ & $<0.001$ \\
\hline Age & $0.1(0.10)$ & 0.287 & $4.19(3.88)$ & 0.280 \\
\hline Height & $-0.15(0.16)$ & 0.363 & $-6.55(6.32)$ & 0.301 \\
\hline Weight & $-0.21(0.19)$ & 0.258 & $2.97(7.43)$ & 0.689 \\
\hline BSA & $21.99(18.83)$ & 0.243 & $-962.7148(721.05)$ & 0.182 \\
\hline Parous_previous PE & $-3.12(1.55)$ & 0.052 & $-158.61(58.99)$ & 0.007 \\
\hline Parous-no previous PE & $-1.32(1.67)$ & 0.430 & $-114.45(63.64)$ & 0.072 \\
\hline Ethnicity & $-0.5(0.29)$ & 0.095 & $-4.54(11.36)$ & 0.689 \\
\hline \multicolumn{3}{|l|}{$\begin{array}{l}\text { Random part } \\
\text { Variances (expressed in SD) due to random effects }\end{array}$} & \multicolumn{2}{|c|}{$\begin{array}{l}\text { Random part } \\
\text { Variances (expressed in SD) } \\
\text { due to random effects }\end{array}$} \\
\hline $\begin{array}{l}\text { Individual SD, estimate (SE) } \\
\text { Residual SD, estimate (SE) }\end{array}$ & \multicolumn{2}{|l|}{$\begin{array}{c}3.96536(0.653656) \\
7.564444(0.3559312)\end{array}$} & \multicolumn{2}{|l|}{$\begin{array}{l}199.2986(17.1863) \\
178.6215(8.417629)\end{array}$} \\
\hline \multicolumn{3}{|l|}{ Model specifications } & \multicolumn{2}{|l|}{ Model specifications } \\
\hline $\begin{array}{l}\text { Log likelihood } \\
\text { AIC } \\
\text { BIC } \\
\text { LR test for random part } \\
\text { (null hypothesis: variance due to random effects }=0 \text { ) }\end{array}$ & $\begin{array}{l}-1234.3387(p<0.001) \\
\quad 2490.677 \\
2533.115 \\
p=0.0001\end{array}$ & & $\begin{array}{l}-2331.4245(p<0.001) \\
4684.849 \\
4727.128 \\
p<0.001\end{array}$ & \\
\hline
\end{tabular}

activity respond well to $\beta$-blockers and ACE inhibitors, while those with low renin activity respond poorly. ${ }^{31}$ Hypertension in black and elderly, compared with younger and white populations, is characterised by low renin. ${ }^{32} 33$

This distinct pathophysiology of hypertension in black patients has formed the basis of NICE clinical guidance which recommends antihypertensive therapy on the basis of age and ethnicity, as a proxy for renin activity. ${ }^{1}$ According to this guidance, older and black hypertensive patients, who are likely to have lower renin activity, should not be prescribed $\beta$-blockers or ACE inhibitors as first-line therapy. ${ }^{1}$

Other distinct pathophysiological pathways for hypertension in black populations have been proposed, associating low renin levels with sodium retention. Sowers et $a \vec{l}^{4}$ have shown that hypertensive compared with normotensive black patients have lower levels of dopamine, a natriuretic substance, and Luft $e t a l^{35}$ have demonstrated that black, compared with white patients, are more susceptible to the hypertensive effects of sodium and demonstrate impaired excretion of a salt load. Despite the low circulating renin levels in black hypertensive populations, a 2006 study by Stewart $e t a l^{8}$ found that this group have paradoxically high aldosterone levels. It could be this is owing to genetic polymorphisms which may have a role in altering the sensitivity of aldosterone release in response to angiotensin II. ${ }^{36}$ Prima facie, this mechanism may explain some of the reduced efficacy of $\beta$-blockade in lowering BP among black populations, since aldosterone levels, even on a background of suppressed renin, would likely remain elevated given these differing polymorphisms.

\section{Pregnancy haemodynamic adaptation}

In normal pregnancies, there is a large drop in PVR with an increase of over $40 \%$ in plasma volume and a rise in $\mathrm{CO}^{37}$ This rise in volume is driven partly by the activation of the renin-angiotensin system (RAS) ${ }^{38}$ with more than a trebling of the serum concentration of angiotensin II in the third trimester, compared with levels outside pregnancy. ${ }^{39}$ Plasma renin concentrations also increase in pregnancy by about $50 \%$ above the levels observed outside of pregnancy. ${ }^{39}$ Pregnancy adaptation leads to a hyperdynamic circulation with upregulation of the RAS.

In hypertensive disorders of pregnancy, this hyperdynamic state is exaggerated further. Bosio et al have shown that during the preclinical phase in preeclampsia, there is a higher CO and lower PVR than in pregnancies not destined to develop this condition. In pregnancy-induced hypertension, this hyperdynamic state is maintained throughout pregnancy without the 'cross-over' to a vasoconstricted low cardiac output state that occurs in pre-eclampsia. ${ }^{40}$ Given the hyperdynamic and high renin state which evolves early in normal gestations, and which is evident and exaggerated in preclinical phases of those pregnancies destined to be 
Table 4 Summary of multilevel linear mixed-effects models for cardiac output, heart rate and stroke volume

\begin{tabular}{|c|c|c|c|c|c|c|}
\hline \multirow[b]{2}{*}{$\begin{array}{l}\text { Variable } \\
\text { Fixed part }\end{array}$} & \multicolumn{2}{|l|}{ Cardiac output } & \multicolumn{2}{|l|}{ Heart rate } & \multicolumn{2}{|l|}{ Stroke volume } \\
\hline & Estimate (SE) & p Value & \multicolumn{2}{|l|}{ Estimate (SE) } & \multicolumn{2}{|l|}{ Estimate (SE) } \\
\hline Intercept & $-7.57(3.03)$ & 0.012 & 121.52 (22.89) & $<0.001$ & $-132.3844(40.88)$ & 0.001 \\
\hline Time & $-0.04(0.05)$ & 0.398 & $-1.55(0.44)$ & $<0.001$ & $0.70(0.59)$ & 0.239 \\
\hline Age & $-0.02(0.02)$ & 0.202 & $-0.23(0.15)$ & 0.133 & $0.036(0.28)$ & 0.898 \\
\hline Height & $0.04(0.03)$ & 0.174 & $-0.09(0.25)$ & 0.712 & $0.96(0.45)$ & 0.033 \\
\hline Weight & $-0.01(0.03)$ & 0.787 & $0.204(0.29)$ & 0.495 & $0.23(0.533)$ & 0.664 \\
\hline BSA & $4.45(3.84)$ & 0.246 & $-13.07(29.00)$ & 0.653 & $14.36(51.68)$ & 0.781 \\
\hline Parous-previous PE & $0.79(0.31)$ & 0.012 & $2.97(2.38)$ & 0.213 & $4.45(4.26)$ & 0.296 \\
\hline Parous-no previous PE & $0.70(0.34)$ & 0.038 & $3.97(2.57)$ & 0.1123 & $2.01(4.59)$ & 0.661 \\
\hline Ethnicity & $-0.008(0.06)$ & 0.884 & $0.32(0.45)$ & 0.481 & $-0.26(0.82)$ & 0.751 \\
\hline $\begin{array}{l}\text { Random part } \\
\text { Variances (expressed in SD) due } \\
\text { to random effects }\end{array}$ & & & \multicolumn{2}{|c|}{$\begin{array}{l}\text { Variances (expressed } \\
\text { in SD) due to random } \\
\text { effects }\end{array}$} & \multicolumn{2}{|c|}{$\begin{array}{l}\text { Random part } \\
\text { Variances (expressed in } \\
\text { SD) due to random effects }\end{array}$} \\
\hline Individual SD, estimate (SE) & \multicolumn{2}{|c|}{$1.120924(0.0871327)$} & \multicolumn{2}{|c|}{$8.245412(0.6776951)$} & \multicolumn{2}{|c|}{$15.42569(1.153087)$} \\
\hline Residual SD, estimate (SE) & \multicolumn{2}{|c|}{$0.7596877(0.0358327)$} & \multicolumn{2}{|c|}{$6.585155(0.3094017)$} & \multicolumn{2}{|c|}{$8.85682(0.418325)$} \\
\hline Model specifications & & & \multicolumn{2}{|c|}{ Model specifications } & \multicolumn{2}{|c|}{ Model specifications } \\
\hline $\begin{array}{l}\text { Log likelihood } \\
\text { AIC } \\
\text { BIC } \\
\text { LR test for random part (null } \\
\text { hypothesis: variance due to random } \\
\text { effects=0) }\end{array}$ & $\begin{array}{c}-522.56485(p<0.00 \\
1067.13 \\
1109.409 \\
p<0.001\end{array}$ & & $\begin{array}{l}239.7218(p=0.01) \\
2501.444 \\
2543.786 \\
p<0.001\end{array}$ & & $\begin{array}{c}-1364.1167(p<0.00 \\
2750.233 \\
2792.512 \\
p<0.001\end{array}$ & \\
\hline
\end{tabular}

complicated by hypertension, it is unsurprising that our study shows that labetalol is effective in reducing BP irrespective of ethnicity.

It is a limitation of our study that we did not measure renin and aldosterone levels. We cannot therefore show the interaction with ethnicity and haemodynamics. However, there are extremely diverse hormonal shifts in pregnancy including thyroid function, oestrogen and progesterone changes that would need to be studied in addition to the activity of the RAS. The cardiovascular end point of these hormonal changes is haemodynamic variables, which we have studied in this work. In addition, as there were no available data in the literature on the serial haemodynamic changes following acute treatment with labetalol in pregnancy, we could not power this study prior to its initiation. However, the repeat measure analysis should add strength to these results as they reflect longitudinal changes with each individual acting as its own control.

\section{CONCLUSION}

This is the first study that reports the haemodynamic changes over time with labetalol therapy in different ethnic groups in pregnancy. In conclusion, in the acute phase of BP control in pregnancy with labetalol, ethnicity is not an independent predictor of haemodynamic changes. In both black and white populations, labetalol effects a decrease in maternal heart rate and vascular resistance and is effective in controlling $\mathrm{BP}$, but it has a slightly greater sustained efficacy in white compared with black populations.

Contributors DS collected and analysed the data and contributed to the preparation of the manuscript. MB collected the data and contributed to the preparation of the manuscript. DP helped collect the data and contributed to the manuscript. IP performed the statistical analyses and helped prepare the manuscript. JBC was involved in planning the study, and helped review the results and contributed to the preparation of the manuscript. NAK planned and oversaw the project, contributed to the statistical analyses and guided the preparation of the manuscript.

Funding The study was partly funded by a grant from The King's College Hospital Charity (Registered Charity 230729).

Competing interests None declared.

Ethics approval NRES Committee London, Fulham. REC reference: 12/LO/ 1593.

Provenance and peer review Not commissioned; externally peer reviewed. Data sharing statement No additional data are available.

Open Access This is an Open Access article distributed in accordance with the Creative Commons Attribution Non Commercial (CC BY-NC 4.0) license, which permits others to distribute, remix, adapt, build upon this work noncommercially, and license their derivative works on different terms, provided the original work is properly cited and the use is non-commercial. See: http:// creativecommons.org/licenses/by-nc/4.0/ 


\section{REFERENCES}

1. Hypertension - clinical management of primary hypertension in adults ( $\mathrm{Cg}$ 127). London: National Institute for Health and Care Excellence 2011.

2. Lim SS, Vos T, Flaxman AD, et al. A comparative risk assessment of burden of disease and injury attributable to 67 risk factors and risk factor clusters in 21 regions, 1990-2010: a systematic analysis for the Global Burden of Disease Study 2010. Lancet 2012;380:2224-60.

3. Cappuccio FP, Cook DG, Atkinson RW, et al. Prevalence, detection, and management of cardiovascular risk factors in different ethnic groups in South London. Heart 1997;78:555-63.

4. Turnbull F, Blood Pressure Lowering Treatment Trialists' Collaboration. Effects of different blood-pressure-lowering regimens on major cardiovascular events: results of prospectively-designed overviews of randomised trials. Lancet 2003;362:1527-35.

5. Hypertension in pregnancy - the management of hypertensive disorders during pregnancy ( $\mathrm{Cg}$ 107). National Institute for Health and Care Excellence, 2011.

6. Brown MJ. Hypertension and ethnic group. BMJ 2006;332:833

7. Brown MJ. Personalised medicine for hypertension. BMJ 2011;343: d4697.

8. Stewart AD, Millasseau SC, Dawes M, et al. Aldosterone and left ventricular hypertrophy in Afro-Caribbean subjects with low renin hypertension. Am J Hypertens 2006;19:19-24.

9. Brown MJ. A rational basis for selection among drugs of the same class. Heart 2003;89:687-94.

10. Gupta AK, Poulter NR, Dobson J, et al. Ethnic differences in blood pressure response to first and second-line antihypertensive therapies in patients randomized in the ASCOT Trial. Am J Hypertens 2010;23:1023-30.

11. Frishman WH. Properties of labetalol, a combined alpha- and beta-blocking agent, relevant to the treatment of myocardial ischemia. Cardiovasc Drugs Ther 1988;2:343-53.

12. Rogers RC, Sibai BM, Whybrew WD. Labetalol pharmacokinetics in pregnancy-induced hypertension. Am J Obstet Gynecol 1990;162:362-6.

13. Davey DA, MacGillivray I. The classification and definition of the hypertensive disorders of pregnancy. Am J Obstet Gynecol 1988;158:892-8.

14. Royston $\mathrm{P}$, Wright EM. How to construct 'normal ranges' for fetal variables. Ultrasound Obstet Gynecol 1998;11:30-8.

15. Raval NY, Squara P, Cleman M, et al. Multicenter evaluation of noninvasive cardiac output measurement by bioreactance technique. J Clin Monit Comput 2008;22:113-19.

16. Kametas NA, McAuliffe F, Cook B, et al. Maternal left ventricular transverse and long-axis systolic function during pregnancy. Ultrasound Obstet Gynecol 2001;18:467-74.

17. Beevers G, Lip GY, O'Brien E. ABC of hypertension: blood pressure measurement. Part II-conventional sphygmomanometry: technique of auscultatory blood pressure measurement. $B M J$ 2001;322:1043-7.

18. Chung $Y$, de Greeff A, Shennan A. Validation and compliance of a home monitoring device in pregnancy: microlife Watchbp Home. Hypertens Pregnancy 2009;28:348-59.

19. Royston P, Altman DG. Design and analysis of longitudinal studies of fetal size. Ultrasound Obstet Gynecol 1995;6:307-12.

20. Collis T, Devereux RB, Roman MJ, et al. Relations of stroke volume and cardiac output to body composition: the strong heart study. Circulation 2001;103:820-5.
21. Turan OM, De Paco C, Kametas N, et al. Effect of parity on materna cardiac function during the first trimester of pregnancy. Ultrasound Obstet Gynecol 2008;32:849-54.

22. Opie LH. Role of vasobilation in the antihypertensive and antianginal effects of labetalol: implications for therapy of combined hypertension and angina. Cardiovasc Drugs Ther 1988;2:369-76.

23. Mehta J, Cohn JN. Hemodynamic effects of labetalol, an alpha and beta adrenergic blocking agent, in hypertensive subjects. Circulation 1977;55:370-5.

24. Materson BJ, Reda DJ, Cushman WC, et al. Single-drug therapy for hypertension in men. A comparison of six antihypertensive agents with placebo. The Department of Veterans Affairs

Cooperative Study Group on Antihypertensive Agents. N Engl J Med 1993;328:914-21.

25. Brewster LM, van Montfrans GA, Kleijnen J. Systematic review: antihypertensive drug therapy in black patients. Ann Intern Med 2004;141:614-27.

26. Sehgal AR. Overlap between whites and blacks in response to antihypertensive drugs. Hypertension 2004;43:566-72.

27. Flamenbaum W, Weber MA, McMahon FG, et al. Monotherapy with labetalol compared with propranolol. Differential effects by race. $J$ Clin Hypertens 1985;1:56-69.

28. Lucas $\mathrm{C}$, Jenkins $\mathrm{P}$, Mendels $\mathrm{J}$, et al. The effectiveness of labetalol compared to hydrochlorothiazide in hypertensive black patients. J Natl Med Assoc 1991;83:866.

29. Townsend RR, DiPette DJ, Goodman R, et al. Combined alpha/ beta-blockade versus beta 1-selective blockade in essential hypertension in black and white patients. Clin Pharmacol Ther 1990;48:665-75.

30. Jennings K, Parsons V. A study of labetalol in patients of European, West Indian and West African origin. Br J Clin Pharmacol 1976;3 (Suppl 3):773-5.

31. Brown MJ. Heterogeneity of blood pressure response to therapy. Am J Hypertens 2010;23:926-8.

32. Helmer OM. Renin activity in blood from patients with hypertension. CMAJ 1964;90:221

33. James GD, Sealey JE, Müller $F$, et al. Renin relationship to sex, race and age in a normotensive population. J Hypertens Suppl 1986;4: S387-9.

34. Sowers JR, Zemel MB, Zemel $P$, et al. Salt sensitivity in blacks. Salt intake and natriuretic substances. Hypertension 1988;12:485-90.

35. Luft FC, Rankin LI, Bloch R, et al. Cardiovascular and humoral responses to extremes of sodium intake in normal black and white men. Circulation 1979;60:697-706.

36. Nicod J, Bruhin D, Auer L, et al. A biallelic gene polymorphism of CYP11B2 predicts increased aldosterone to renin ratio in selected hypertensive patients. J Clin Endocrinol Metab 2003;88:2495-500.

37. Hytten F. Blood volume changes in normal pregnancy. Obstet Gynecol Surv 1986;41:426-8.

38. Cheung KL, Lafayette RA. Renal physiology of pregnancy. Adv Chronic Kidney Dis 2013;20:209-14.

39. Baker PN, Broughton Pipkin F, Symonds EM. Platelet angiotensin II binding and plasma renin concentration, plasma renin substrate and plasma angiotensin II in human pregnancy. Clin Sci (Lond) 1990;79:403-8.

40. Bosio PM, McKenna PJ, Conroy R, et al. Maternal central hemodynamics in hypertensive disorders of pregnancy. Obstet Gynecol 1999;94:978-84. 